British Journal of Industrial Medicine 1986;43:505-506

\title{
Editorial
}

\section{Cement workers and cancer: epidemiology at work?}

In the recent review of the role of epidemiology and epidemiologists in the study of occupational cancer Sir Richard Doll noted that it was "hardly possible to open a journal devoted to occupational or environmental health without finding a reference to the possibility of a new hazard of occupational cancer." general theme was that epidemiologists should give more attention to the solution of the scientific problems of epidemiology, perhaps evolving a set of guidelines for the discovery and investigation of possible new hazards, and should be able and willing to admit, when appropriate, the inadequacy of accumulated evidence against any incriminated agent.

The health of cement workers has been studied at least since the turn of the century. There is clear evidence of a risk of occupational dermatitis and contradictory evidence of any impairment to lung function arising from exposure to cement dust. ${ }^{2-4}$ Two recent reports, however, have raised the possibility that exposure to cement is carcinogenic-one report suggesting lung cancer (M J B Farebrother, et al, unpublished observations), the other stomach cancer. ${ }^{5}$ The first study was a case-control review of lung cancer among naval dockyard workers that found a significant excess of cases in men who had formerly worked in cement manufacture. The second was a cohort study of men identified as cement workers in 1939, designed to test the hypothesis (raised elsewhere ${ }^{6}$ ) that heavy exposure to dust was associated with excess mortality from stomach cancer. A statistically significant excess of stomach cancer was found.

Having raised two separate possible new hazards from one substance, this is clearly an excellent case for epidemiologists to respond to Doll's exhortations to give more attention to the early resolution of suggested occupational hazards.

His criteria for establishing carcinogenicity (closely adopted from IARC recommendations ${ }^{7}$ ) are that a positive association between exposure and disease

(a) is not explicable by bias in recording or detection, confounding, or by chance;

(b) varies appropriately with intensity and duration of exposure and time after exposure begins and ends, and

(c) is observed repeatedly in different circumstances. ${ }^{1}$

The third criterion can be met only by further studies of the health of cement workers and the current issue of the journal contains two such studies, one looking particularly at lung cancer mortality, ${ }^{8}$ the other at stomach cancer mortality. ${ }^{9}$ Thus more research is still needed but this does not preclude more detailed critical reviews of the existing evidence.

In the first study Rafusson and Johannesdottir report a cohort study of the mortality of "masons"- that is, cement and concrete finishers-in Iceland showing a significant excess of lung cancer. ${ }^{8}$ It was hypothesised that this excess might be associated with the presence of hexavalent chromium in the cement. Amandus reports a cohort study of workers at 23 United States cement plants with a not significantly raised SMR for stomach cancer. ${ }^{9}$ It would be unreasonable to expect these additional studies to confirm or refute satisfactorily either of the hypothesised associations - more evidence of repeatability would be necessary. It is appropriate, however, to consider this additional evidence from the viewpoint of Doll's criteria. The regular review of epidemiological evidence by such criteria should allow an earlier settlement of the validity of a suggested new hazard.

In attempting to exclude the possibility that the association is due to chance it is not sufficient merely to look for statistical significance. It is also important to ensure that the data which led to the hypothesis being formed are kept separate from subsequent data gathered to test the hypothesis. ${ }^{1}$ In this instance this implies that the initial case-control and cohort studies, having raised their respective hypotheses, should not influence the examination of the validity of the hypotheses, which will rely so far on the two studies in the current issue of the journal (plus, in the case of lung cancer, the initial cohort study which raised the stomach cancer hypothesis also reported mortality from lung cancer-a non-significant deficit).

Both the Icelandic and United States studies have attempted to allow or account for the possibility of confounding variables. Smoking is excluded as a major contributory factor to the excess of lung cancer in the Icelandic study not by evidence of smoking history of the workforce but by a consideration of the mortality from other smoking related diseases and by the size of the measured excess risk. The United States study controlled for possible ethnic and country of birth variations in mortality from stomach cancer. Neither study considered socioeconomic status as a possible confounder even though this is known to 
affect the mortality of both diseases. ${ }^{6}$ Both studies compared the cohorts' mortality against national mortality rates, making no allowance for regional variations. This should not be a problem in the Icelandic study as the workforce was not obviously centred in large plants and was presumably employed throughout the country. The 23 cement plants in the United States study were distributed across the country, but cement manufacture tends to centre in areas of similar geographical and geological characteristics which may imply similar mortality patterns.

Both studies attempted to assess some aspects of the effect of different degrees of exposure. In the Icelandic study each member of the cohort has a minimum four years exposure and the cohort's mortality is analysed by period since first exposure. Data on the intensity and duration of exposure are not available but the study shows a sharply increasing excess risk of lung cancer with period since first exposure. The United States study analyses mortality by period since first exposure and by years of exposure, finding no positive association of increased risked with increased exposure or time since exposure. Such associations, however, would have to be strong to show up when only 27 deaths from stomach cancer are analysed in total. No evidence on intensity of exposure is available.

This brief review of how these two studies match up to the criteria listed earlier for establishing or refuting causality out of hypothesised association is not intended to appear especially critical. The limitations of these studies are common to most early epidemiological examinations of a new hypothesised association. The priority at this stage is to assemble as much information as is available on the existence and nature of any association. Readily available data are rarely ideal, but it would be wasteful to enter a detailed study recording full exposure details on limited prior evidence on the association being studied. Acceptance of the more "rough and ready" nature of the preliminary round of examination of a new hypothesis should not preclude the type of review of the strength of evidence touched on here. More formalised examination of the strength of epidemiological evidence should allow an earlier and more definitive acceptance or rejection of the hypothesis.
In the specific case of the two hypotheses consid- $\frac{\pi}{\Phi}$ ered here in neither example is the evidence yet? sufficient to reach any conclusion. Further rough and $\overrightarrow{\vec{\rho}}$ ready evidence is necessary even before a detailed $\frac{\text { ? }}{\circ}$ study of exposures and effects is justified. With the agreement of the cement industry and trade unions in $\frac{\bar{c}}{\mathrm{c}}$. the United Kingdom a further 1939 based cohort $\frac{\vec{\sigma}}{\overrightarrow{0}}$

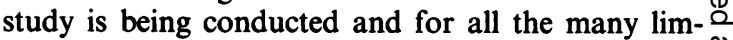
itations of the approach it has the advantage of rela- $ळ$ tive speed-the findings should be available in the $\vec{\circ}$ first half of 1986.

This review has concentrated on the interpretation $\vec{\omega}$ of statistical data, which partly explains the absence of discussion of biological plausibility in considering $\frac{\mathbb{D}}{\square}$ causality. In practical terms, as Bradford-Hill has noted, biological plausibility is helpful in establishing $\stackrel{\omega}{\omega}$ causality but cannot be demanded-what is biologi- $\infty$ cally plausible depends on biological knowledge. ${ }^{10} \mathrm{O}$ Few would stop investigating a consistent and $\mathrm{o}$

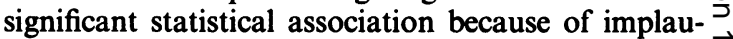
sibility.

Medical Statistics Division, M McDOWALL $\frac{\text { ह }}{\mathrm{C}}$

Office of Population Censuses and Surveys, London $W C 2 B$ 6JP.

\section{References}

${ }^{1}$ Doll R. Occupational cancer: a hazard for epidemiologists. Int $J \supseteqq$ Epidemiol 1985;14:22-31.

${ }^{2}$ Hoffman FL. Mortality from respiratory diseases in dusty trades. (US Department of Labor). Washington: Government Printing Office, 1918:227-41.

${ }^{3}$ Fleetwood L, Santan CA. Medical aspects of the manufacture and $\overline{\mathrm{O}}$ use of Portland cement. Edinburgh: Institute of Occupational Medicine, 1979. (Report TM/79/20.)

4 Bazas T. Effects of occupational exposure to dust on the respiratory system of cement workers. J Soc Occup Med 1980;30:31-6.

${ }^{5} \mathrm{McD}$ owall ME. A mortality study of cement workers. Br J Ind Med 1984:41:179-82.

${ }^{6}$ Office of Population Censuses and Surveys. Registrar General's decennial supplement-occupational mortality 1970-2. London: 3 HMSO, 1978.

${ }^{7}$ International Agency for Research on Cancer. Chemicals, industrial $\stackrel{\mathrm{O}}{3}$ processes and industries associated with cancer in humans. Lyon: IARC, 1982. (IARC monographs, suppl 4.)

${ }^{8}$ Rafnsson V, Johannesdottir SG. Mortality among masons in Iceland. Br J Ind Med 1986;43:522-5.

${ }^{9}$ Amandus HE. Stomach cancer mortality in US cement plant and quarry workers, 1950-80. $\mathrm{Br} J$ Ind $\mathrm{Med}$ 1986;43:526-8.

${ }^{10}$ Bradford-Hill. A short textbook of medical statistics. London: Hodder and Stoughton, 1984. 